\title{
Effect of dragon fruit extract on oxidative stress and aortic stiffness in streptozotocin-induced diabetes in rats
}

\author{
Kolla R. L. Anand Swarup, Munavvar A. Sattar, Nor A. Abdullah', Mohammed H. Abdulla, \\ Ibrahim M. Salman, Hassaan A. Rathore, Edward J. Johns ${ }^{2}$
}

Physiology Research Lab, School of Pharmaceutical Sciences, Universiti Sains Malaysia, Minden - 11800, Penang, ${ }^{1}$ Departments of Pharmacology, Faculty of Medicine, Universiti Malaya, Kuala Lumpur, Malaysia, ${ }^{2}$ Department of Physiology, Aras Windle, University College Cork, College Road, Cork, Ireland

Submitted: 14-11-2009

Revised: 26-01-2010

Published: 13-03-2010

\section{A B S T R A C T}

Cardiovascular complications are consistently observed in diabetic patients across all age groups. The objective of the present study was to investigate the effect of aqueous extract of the fruit pulp of Hylocereus undatus (DFE) on aortic stiffness and oxidative stress in streptozotocin (STZ)-induced diabetes in rats. Twenty-four male, Sprague-Dawley rats were randomized into four groups: I (control), II (diabetic), III (DFE, $250 \mathrm{mg} / \mathrm{kg}$ ) and IV (DFE $500 \mathrm{mg} / \mathrm{kg}$ ). Diabetes was induced in groups II, III and IV by intraperitoneal (i.p.) injection of STZ (40 mg/kg). After confirmation of diabetes, group III and IV received DFE for 5 weeks. Pulse wave velocity (PWV) was used as a marker of aortic stiffness and was determined at the end of 5 weeks. DFE significantly decreased $(P<0.05)$ the fasting blood glucose levels in diabetic rats, but not to normal levels. Systolic blood pressure, pulse pressure and PWV were significantly increased $(P<0.05)$ in diabetic rats at the end of 5 weeks in comparison with control group. DFE treatment significantly decreased $(P<0.05)$ these elevations. Oxidative damage was observed in group II after 5 weeks. Plasma malondialdehyde levels significantly decreased $(P<0.05)$, while superoxide dismutase and total antioxidant capacity significantly increased $(P<0.05)$ with DFE treatment in comparison with group II. These data demonstrate that DFE treatment was effective in controlling oxidative damage and decreasing the aortic stiffness measured by PWV in STZ-induced diabetes in rats.

Key words: Arterial stiffness, diabetes, Hylocereus undatus, pulse wave velocity, streptozotocin

\section{INTRODUCTION}

Cardiovascular disease is the major cause of mortality in the western world and accounts for up to a third of all deaths worldwide. Most of these deaths occurred in low- and middle-income countries. It is estimated to be the leading cause of death in developing countries by 2010. ${ }^{[1]}$ Aortic stiffness is predictive of adverse cardiovascular events, in a range of subpopulations and different disease types. Arterial stiffness can be determined by measuring the pulse wave velocity (PWV) ${ }^{[2]}$ Pulse wave travels faster in a stiffer vessel. Hence PWV has been widely used as a surrogate marker for arterial stiffness and vascular diseases. ${ }^{[3]}$ Association of higher cardiovascular risk with increased

Address for correspondence:

Kolla R. L. Anand Swarup, Physiology Research Lab,

School of Pharmaceutical Sciences, Universiti Sains Malaysia,

Minden, 11800 Pulau Penang, Malaysia.

E-mail: kollanand@yahoo.co.in

DOI: $10.4103 / 0974-8490.60582$ pulse wave velocity was demonstrated in 710 hypertensive subjects. ${ }^{[4]}$

Cardiovascular complications are observed in both type 1 and type 2 diabetic patients. Diabetes increases the risk of vascular complications at least by twofold. Macrovascular disease (cerebrovascular, coronary artery and peripheral vascular disease) is the cause of death in $70 \%$ to $80 \%$ of diabetic patients. ${ }^{[5,6]}$ Impairment in contractile function of the vascular smooth muscle cells is observed in rats treated with streptozotocin (STZ), which may be because of changes in vasoactive substances and vasomotor responsiveness. ${ }^{[7]}$ The mechanical properties of the arterial system in STZdiabetic rats may be altered by changes in cellular physiology of the diabetic conducting arteries. ${ }^{[8]}$ Oxidative stress plays an important role in the development of vascular complications associated with diabetes. ${ }^{\left[{ }^{[9]}\right.}$ Antioxidants have been reported to have beneficial effects in cardiovascular diseases associated with overproduction of reactive oxygen species.

Polyphenolics, carotenoids, thiols, tocopherols and 
glucosinolates, commonly found in fruits, vegetables and grains, help to combat oxidative stress in the body and improve human health. ${ }^{[10,11]}$ Consumption of fresh fruits and vegetables has been associated with reduced risk of cardiovascular diseases. ${ }^{[12]}$ However, the antioxidant activity and potential health benefits of some plant foods have not been evaluated systematically. The fruits of Hylocereus undatus, known as dragon fruit or red pitaya, are rich in antioxidant betacyanins. ${ }^{[13]} \mathrm{H}$. undatus is a climbing vine cactus, which is native to the tropical forest regions of Mexico and Central and South America. ${ }^{[14]}$

Mayas traditionally used the leaves and flowers of $H$. undatus as a hypoglycemic, diuretic and cicatrizing agent. ${ }^{[15]}$ The rich antioxidants are known to prevent diabetes and cancer, neutralize toxic substances such as heavy metals and reduce cholesterol and high blood pressure. ${ }^{[16]}$ Perez et al. ${ }^{[1]]}$ studied the wound-healing property, and $\mathrm{Wu}$ et al. ${ }^{[18]}$ reported the antioxidant and antiproliferative properties of H.undatus. The objective of the present study was to evaluate the in vivo antioxidant and vascular properties of aqueous extract of the fruit of $H$. undatus in streptozotocin-induced diabetes in rats.

\section{MATERIALS AND METHODS}

\section{Preparation of dragon fruit extract}

Dragon fruits were purchased from the local market, and fresh fruit pulp was extracted with water at a ratio of 1:2 (1 $\mathrm{kg}$ of fresh dragon fruit pulp in $2 \mathrm{~L}$ of water) at ambient temperature for 1 hour. Liquid extract was filtered and concentrated by rotary evaporator. Concentrated liquid extract was then dried into powdered form.

\section{Experimental animals}

Male Sprague-Dawley (SD) rats weighing 275 to $325 \mathrm{~g}$ were used for the study. Animals were obtained from Animal House, Universiti Sains Malaysia, Penang, Malaysia. Rats were acclimatized for 1 week before starting any experiment. Animals were housed in a room at $25^{\circ} \mathrm{C}$ temperature and 12:12-hour light-dark cycle with free access to rat chow (Gold Coin Sdn. Bhd.) and tap water ad libitum. All experimental procedures were approved by, and carried out as per the guidelines of, the Animal Ethics Committee, Universiti Sains Malaysia, Penang, Malaysia.

\section{Preparation of animals}

Animals were randomly divided into four groups $(n=6)$, namely, control (I), diabetic (II), diabetic treated with DFE at a dose of $250 \mathrm{mg} / \mathrm{kg}$ (III) and $500 \mathrm{mg} / \mathrm{kg}$ (IV) body weight. A single intraperitoneal (i.p.) injection of STZ at a dose of $40 \mathrm{mg} / \mathrm{kg}$ (Nova Laboratories, Sdn. Bhd., Selangor, Malaysia) was used to induce diabetes. STZ was dissolved in freshly prepared $0.1 \mathrm{M}$ citrate buffer ( $\mathrm{pH} 4.5)$. Control rats received an equal volume of buffer by i.p. injection. Diabetes was confirmed after 3 days by measuring fasting (overnight) blood glucose levels with the use of glucose oxidase reagent strips (GlucoSure plus, Apex Biotechnology Corp., Hsinchu, Taiwan). Rats with a blood glucose level of $\geq 350 \mathrm{mg} / \mathrm{dL}$ were selected for the study. After confirmation of diabetes, rats of groups III and IV were treated with DFE orally by gavage for 5 weeks. Groups I and II served as a normal and diabetic control, respectively, and did not receive any treatment.

\section{Surgical procedure}

In order to avoid possible involvement of the effects of acute administration, all procedures were conducted 48 hours after the end of treatment period. Overnightfasted rats were anesthetized with an i.p. injection of sodium pentobarbitone (Nembutal ${ }^{\circledR}$, CEVA, France) at a dose of $60 \mathrm{mg} / \mathrm{kg}$. Tracheotomy (PE250, Portex, UK) was performed to facilitate respiration, and the left jugular vein was cannulated to enable the administration of anesthetic $(10 \mathrm{mg} / \mathrm{kg}$ in normal saline) if necessary. For measurement of PWV, the right carotid artery was catheterized (PE50, Portex, UK), and the cannula was pushed up to the level of aortic arch. Similarly, another cannula (PE50, Portex, UK) was introduced into the abdominal aorta through the left iliac artery. For the measurement of mean arterial pressure (MAP), the cannulae were connected to a pressure transducer (P23 ID Gould, Statham Instrument, Nottingham, UK), which in turn was hooked up to a computerized data acquisition system (PowerLab, ADInstrumentation, Sydney, Australia).

\section{Measurement of pulse wave elocity}

Pulse wave velocity was measured as described by Wang et al. ${ }^{[2]}$ Briefly, pulse pressure waves from the two pressure transducers were simultaneously recorded and displayed on a data acquisition system. Blood sample was collected at the end of the experiment and the animal euthanized with sodium pentobarbitone $(200 \mathrm{mg} / \mathrm{kg})$. Full length of aorta was exposed and the distance between the tips of the two cannulae was measured $(\mathrm{L})$. The propagation time $(\mathrm{t})$ for the blood pressure wave to move from the aortic arch to the abdominal aorta was measured manually by the time delay between the upstrokes (foot) of each pressure wave front using 'foot-to-foot' technique. ${ }^{[2]}$ Pulse wave velocity was calculated by dividing $L$ by $t$ and expressed in units of meters per second.

Mean arterial pressure (MAP), systolic arterial pressure (SAP), diastolic arterial pressure (DAP), and pulse pressure $(\mathrm{PP})$ were determined from measurements made by the pressure transducer located in the aortic arch and were calculated by using Chart v5 software (PowerLab, ADInstrumentation, Sydney, Australia). 
Lipid peroxidation and antioxidant enzymes activities The extent of lipid peroxidation was assessed by measuring the malondialdehyde (MDA) formation by using thiobarbituric acid reaction method. ${ }^{[19]}$ Malondialdehyde reacts with thiobarbituric acid in acidic medium to give a pink-colored pigment at $95^{\circ} \mathrm{C}$. The absorbance of the colored product was read at $532 \mathrm{~nm}$. Assay procedure was carried out according to the kit instructions (Nanjing Jiancheng Bioengineering Institute, China).

Superoxide dismutase (SOD) activity in plasma was determined by the method of Oyanagui et al. ${ }^{[20]}$ as per the kit instructions (Nanjing Jiancheng Bioengineering Institute, China). Briefly the test principle is as follows: superoxide anions are generated by xanthine and xanthine oxidase system. These superoxide anions oxidize hydroxylamine leading to formation of nitrite. This nitrite reacts with naphthalene diamine and sulfanilic acid to produce a colored product. SOD in the sample reduces superoxide anion concentration, thus lowering the colorimetric signal and absorbance, which is measured at $550 \mathrm{~nm}$. One unit of SOD activity is defined as that amount of enzyme required to inhibit the reduction of SOD by $50 \%$ under the specified conditions. Total antioxidant capacity (TAC) in plasma was quantified by the method of Miller et al. ${ }^{[21]}$ (Cayman Chemical, AnnArbor, MI, USA). The principle is based on the inhibition of 2, 2'-Azino-di-[3-ethylbenzthiazdine sulphonate] radical $\left(\mathrm{ABTS}^{\mathrm{R}}\right)$ by antioxidants in the plasma. Radical cation $\mathrm{ABTS}^{\mathrm{R}+}$ was generated by incubation of $\mathrm{ABTS}^{\mathrm{R}}$ with a peroxidase (metmyoglobin) and $\mathrm{H}_{2} \mathrm{O}_{2}$. The amount of the $\mathrm{ABTS}^{\mathrm{R}+}$ produced can be monitored by reading the absorbance at $750 \mathrm{~nm}$. The capacity of the antioxidants in the sample to prevent $\mathrm{ABTS}^{\mathrm{R}}$ oxidation is compared with that of Trolox and is quantified as millimolar Trolox equivalents.

\section{Statistics}

All results were expressed as mean \pm S.E.M. for the number of animals $(n)$ indicated. Mean values were compared by one-way ANOVA followed by Bonferonni/ Dunnett (all mean) post hoc test at a significance level of
5\% $(P<0.05)$. Statistical analysis was processed with SUPERANOVA (Abacus Inc., Barkeley, CA, USA).

\section{RESULTS}

\section{Body weight and blood glucose levels}

As indicated in Table 1, the final body weight of all the diabetic rats decreased significantly $(P<0.05)$ in comparison with their initial body weight. But the body weight of the normal control rats significantly increased $(P<0.05)$ from the initial levels. After the end of the treatment period, fasting blood glucose levels in the DFE-treated groups were significantly $(P<0.05)$ lower than the diabetic control group II. However, there was no significant $(P>0.05)$ difference in blood glucose levels of groups III and IV.

\section{Blood pressure and Pulse wave velocity}

Systolic arterial pressure in diabetic control group was significantly higher $(P<0.05)$ than the normal control group. On the other hand, SAP of DFE-treated diabetic rats had come back to that of normal control group. In contrast to SAP, there was no significant difference in the DAP between any of the groups [Table 1]. The MAP of the normal control group did not show any significant difference from other groups. However, the pulse pressure of the diabetic control group was significantly higher $(P<0.05)$ than that of the normal control group. The PWV of group II $(6.54 \pm 0.12 \mathrm{~m} / \mathrm{s})$ was significantly greater $(P<0.05)$ than that of group I $(5.46 \pm 0.09 \mathrm{~m} / \mathrm{s})$. Treatment with DFE significantly decreased $(P<0.05)$ the PWV, but not to the normal control levels [Figure 1].

\section{Oxidative stress parameters}

Table 2 summarizes the results of total antioxidant activity in plasma, antioxidant enzymes activity (SOD) and levels of oxidative stress marker (MDA) in plasma. MDA levels increased significantly $(P<0.05)$ in group II after the induction of diabetes. Extract treatment significantly decreased the MDA levels, but not to the normal basal values. The basal values of SOD and TAC decreased significantly $(P<0.05)$ in diabetic rats of group II when

\begin{tabular}{|c|c|c|c|c|c|c|c|}
\hline \multirow[t]{2}{*}{ Groups (n $=6$ ) } & \multicolumn{2}{|c|}{ Body weight (g) } & \multirow[t]{2}{*}{ Glucose (mg/dL) } & \multirow[t]{2}{*}{ SAP $(\mathrm{mmHg})$} & \multirow[t]{2}{*}{ DAP (mmHg) } & \multirow[t]{2}{*}{ MAP (mmHg) } & \multirow[t]{2}{*}{ PP (mmHg) } \\
\hline & Initial & Final & & & & & \\
\hline I & $292.8 \pm 5.2$ & $329.2 \pm 5.2$ & $88.3 \pm 2.1$ & $121.0 \pm 1.2$ & $87.8 \pm 1.5$ & $100.2 \pm 1.2$ & $34.0 \pm 0.6$ \\
\hline II & $300.2 \pm 5.3$ & $252.3 \pm 3.3^{a}$ & $452.3 \pm 7.9^{b}$ & $130.2 \pm 1.3^{b}$ & $89.8 \pm 1.0$ & $105.2 \pm 1.6$ & $40.2 \pm 0.9^{b}$ \\
\hline III & $289.5 \pm 2.7$ & $256.3 \pm 6.2^{\mathrm{a}}$ & $273.7 \pm 8.9^{\mathrm{bc}}$ & $124.2 \pm 2.1^{\mathrm{c}}$ & $87.7 \pm 1.7$ & $100.5 \pm 1.7$ & $37.3 \pm 0.8$ \\
\hline IV & $292.5 \pm 4.8$ & $262.3 \pm 3.3^{a}$ & $261.3 \pm 10.2^{\mathrm{bc}}$ & $126.0 \pm 1.7$ & $88.2 \pm 0.9$ & $101.0 \pm 1.3$ & $37.3 \pm 1.0$ \\
\hline \multicolumn{8}{|c|}{$\begin{array}{l}\text { a } P<0.05 \text { compared with group I and the initial value of respective groups; }{ }^{b} P<0.05 \text { compared with group } \mathrm{I}^{\mathrm{c}} \mathrm{P}<0.05 \text { compared with group } \mathrm{II} \text {, Body weight, blood glucose } \\
\text { concentrations, systolic arterial pressure (SAP), diastolic arterial pressure (DAP), mean arterial pressure (MAP) and pulse pressure (PP) of groups I (normal control), II } \\
\text { (diabetic control), III (diabetic + DFE } 250 \mathrm{mg} / \mathrm{kg} \text { ) and IV (diabetic + DFE } 500 \mathrm{mg} / \mathrm{kg} \text { ). Values are expressed as mean } \pm \text { S.E.M. Statistical analysis was done by one-way ANOVA } \\
\text { Bonferonni/Dunnett post hoc test for all groups. }\end{array}$} \\
\hline
\end{tabular}




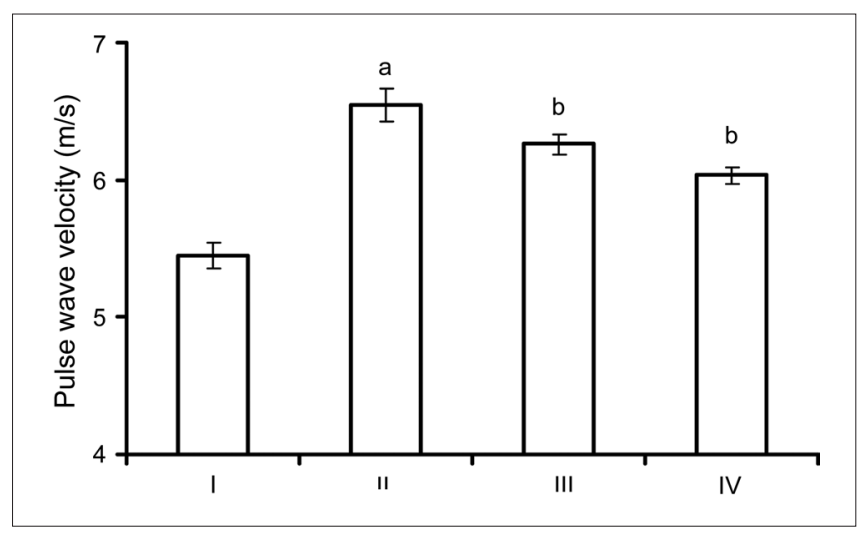

Figure 1: Pulse wave velocity of groups I (normal control), II (diabetic control), III (diabetic + DFE $250 \mathrm{mg} / \mathrm{kg}$ ) and IV (diabetic + DFE $500 \mathrm{mg} / \mathrm{kg})(n=6)$. Values are expressed as mean \pm S.E.M. Statistical analysis was done by one-way ANOVA Bonferonni/ Dunnett post hoc test for all groups.

compared with those of the normal control group. A dosedependent increase in the values of SOD and TAC was observed in extract-treated groups (III and IV).

\section{DISCUSSION}

Oxidative stress plays a major role in the pathogenesis of diabetes and diabetic complications and has been extensively studied for years. Elevated levels of blood glucose increase oxidative stress in diabetic patients and experimental animal models of diabetes. This leads to depletion of the antioxidative defense system and thus promotes free radical generation. ${ }^{[22,23]}$ In the present study, DFE at a dose of 250 and $500 \mathrm{mg} / \mathrm{kg}$ body weight, decreased blood glucose levels significantly but not to normal levels in rats in whom diabetes was induced by STZ. Similar levels of blood glucose in groups III and IV at the end of the treatment period indicate that blood glucose-lowering effect of the extract was limited and could not be increased with dose.

There was no significant change in MAP between the groups; but at the same time, significant increase in pulse pressure and PWV was observed in diabetic rats at the end of 5 weeks in comparison with control rats. Earlier studies reported a reduced relaxation of the isolated aortic rings of diabetic rats in response to the vasodilators acetylcholine and sodium nitroprusside. ${ }^{[24,25]}$ The reduced vasodilator response of diabetic vessels may be responsible for the increase in arterial stiffness, pulse pressure and isolated systolic pressure in the diabetic rats. This may be because of increased oxidative stress, as observed by an increase in lipid peroxidation coupled with decreased TAC and SOD activity. These changes were reversed with the treatment of DFE. This may be because of the antioxidants present in the extract. Even though blood glucose levels did not change with increase in the dose of extract, MDA levels decreased
Table 2: Oxidative stress parameters

\begin{tabular}{lccc}
\hline $\begin{array}{l}\text { Groups } \\
(\mathbf{n}=\mathbf{6})\end{array}$ & $\begin{array}{c}\text { MDA } \\
(\mathbf{n m o l} / \mathbf{m L})\end{array}$ & $\begin{array}{c}\text { SOD } \\
(\mathbf{U} / \mathbf{m L})\end{array}$ & $\begin{array}{c}\text { TAC } \\
(\mathbf{m m o l} / \mathrm{L})\end{array}$ \\
\hline I & $2.713 \pm 0.1$ & $130.688 \pm 3.62$ & $1.805 \pm 0.08$ \\
II & $5.650 \pm 0.22^{\mathrm{a}}$ & $101.938 \pm 3.06^{\mathrm{a}}$ & $1.160 \pm 0.05^{\mathrm{a}}$ \\
III & $4.173 \pm 0.21^{\mathrm{ab}}$ & $115.605 \pm 2.94^{\mathrm{a}}$ & $1.288 \pm 0.10^{\mathrm{a}}$ \\
IV & $3.652 \pm 0.19^{\mathrm{ab}}$ & $127.333 \pm 3.42^{\mathrm{b}}$ & $1.520 \pm 0.12^{\mathrm{b}}$ \\
\hline
\end{tabular}

ap $<0.05$ compared with group I; ${ }^{\mathrm{b}} P<0.05$ compared with group II, Malondialdehyde (MDA), superoxide dismutase (SOD) and total antioxidant capacity (TAC) of groups I (normal control), II (diabetic control), III (diabetic + DFE $250 \mathrm{mg} /$ $\mathrm{kg}$ ) and IV (diabetic $+500 \mathrm{mg} / \mathrm{kg}$ ). Values are expressed as mean \pm S.E.M. Statistical analysis was done by one-way ANOVA Bonferonni/Dunnett post hoc test for all groups.

and TAC and SOD levels increased. This improvement in the oxidative status was accompanied by decrease in PWV, which implies that at higher dose the natural antioxidants present in the extract may be responsible for decreasing the arterial stiffness. Dragon fruit is a good source of several natural antioxidants like betalains, polyphenols and ascorbic acid. As reported in previous studies, ${ }^{[2]]}$ bioavailability of vasorelaxant nitric oxide might be increased by the superoxide-scavenging activity of these antioxidants. Overall, the administration of DFE increased the oxidative defense and protected aorta from hyperglycemic damage in rats in whom diabetes was induced by STZ in this set of experiments.

\section{ACKNOWLEDGMENTS}

We thank Universiti Sains Malaysia (USM), Penang, Malaysia, for the award of USM Fellowship and for providing Postgraduate Research Grant (USM-RU-PRGS 1001/PFARMASI/842013).

\section{REFERENCES}

1. World Health Organization, Cardiovascular Diseases [home page on the internet]. [cited 2009 Oct 11]. Available from: http:// www.who.int/cardiovascular_diseases/en/.

2. Wang $Y X$, Halks-Miller M, Vergona $R$, Sullivan ME, Fitch $R$, Mallari $C$, et al. Increased aortic stiffness assessed by pulse wave velocity in apolipoprotein E-deficient mice. Am J Physiol Heart Circ Physiol 2000;278:H428-34.

3. Lehmann ED, Hopkins KD, Jones RL, Rudd AG, Gosling RG. Aortic distensibility in patients with cerebrovascular disease. Clin Sci (Lond) 1995;89:247-53.

4. Blacher J, Asmar R, Djane S, London GM, Safar ME. Aortic pulse wave velocity as a marker of cardiovascular risk in hypertensive patients. Hypertension 1999;33:1111-7.

5. American Diabetes Association Position Statement. Diabetic nephropathy. Diabetes Care 2003;26:S94-8.

6. Bloomgarden ZT. The epidemiology of complications. Diabetes Care 2002;25:924-32.

7. Williamson JR, Chang K, Tilton RG, Kilo C. Models for studying diabetic complications. In: Creutzfeldt W, Lefebvre P, editors. Diabetes Mellitus: Pathophysiology and Therapy. New York: Springer-Verlag; 1989. p. 142-51.

8. Chang KC, Chen TJ, Peng YI, Li TH, Tseng YZ. Impaired 
vascular dynamics in normotensive diabetic rats induced by streptozotocin: tapered T-tube model analysis. J Theor Biol 2000;204:371-80.

9. Baynes JW. Role of oxidative stress in development of complications in diabetes. Diabetes 1991;40:405-12.

10. Adom KK, Liu RH. Antioxidant Activity of Grains. J Agric Food Chem 2002;50:6182-7.

11. Dragsted LO, Strube M, Larsen JC. Cancer-protective factors in fruits and vegetables: biochemical and biological background. Pharmacol Toxicol 1993;72:116-35.

12. Bazzano LA, Serdula MK, Liu S. Dietary intake of fruits and vegetables and risk of cardiovascular disease. Curr Atheroscler Rep 2003;5:492-9.

13. Wybraniec S, Mizrahi $\mathrm{Y}$. Fruit flesh betacyanin pigments in Hylocereus Cacti. J Agric Food Chem 2002;50:6086-9.

14. Mizrahi Y, Nerd A, Nobel PS. Cacti as Crops. Hortic Rev 1997;18:291-320.

15. Argueta AV, Cano LM, Rodarte ME. Atlas de las Plantas de la Medicina Tradicional Mexicana. Instituto Nacional Indigenista. II. 1994. p. 1170.

16. Gunasena HP, Pushpakumara DKNG, Kariawasam M. Dragon fruit, In: Pushpakumara DKNG, Gunasena HPM, Singh VP editors. Underutilized fruit trees in Sri Lanka. Volume I, New Delhi, India: World agroforestry centre ICRAF; 2007. p. 110-40.

17. Perez G RM, Vargas S R, Ortiz H YD. Wound Healing Properties of Hylocereus undatus on Diabetic Rats. Phytother Res 2005; 19:665-8.

18. Wu LC, Hsu HW, Chen YC, Chiu CC, Lin YI, Ho JA. Antioxidant and antiproliferative activities of red pitaya. Food Chem 2006;95:319-27.

19. Ohkawa H, Ohishi N, Yagi K. Assay for lipid peroxides in animal tissues by thiobarbituric acid reaction. Anal Biochem 1979;95:351-8.

20. Oyanagui $Y$. Reevaluation of assay methods and establishment of kit for superoxide dismutase activity. Anal Biochem 1984;142:290-6.

21. Miller NJ, Rice-Evans C, Davies MJ, Gopinathan V, MilnerA. A novel method for measuring antioxidant capacity and its application to monitoring the antioxidant status in premature neonates. Clin Sci (Lond) 1993;84:407-12.

22. Baynes JW, Thorpe SR. The role of oxidative stress in diabetic complications. Curr Opin Endocrinol 1996;3:277-84.

23. Ihara Y, Toyokuni S, Uchida K, Odaka H, Tanaka T, Ikeda H, et al. Hyperglycemia causes oxidative stress in pancreatic beta-cells of GK rats a model of type 2 diabetes. Diabetes 1999;48:927-32.

24. Laight DW, Carrier MJ, Anggård EE. Antioxidants, diabetes and endothelial dysfunction. Cardiovasc Res 2000;47:457-64.

25. Dresner LS, Wang SP, West MW, Ponomarenko IN, Mueller CM, Wait RB. Nitric oxide inhibition simulates the enhancement of a1-agonist-induced vasoconstriction in diabetes. J Surg Res 1997;70:119-23.

26. Machha A, Achike FI, Mustafa AM, Mustafa MR. Quercetin, a flavonoid antioxidant, modulates endothelium-derived nitric oxide bioavailability in diabetic rat aortas. Nitric Oxide 2007;16:442-7.

Source of Support: Nil, Conflict of Interest: None declared.

\section{Staying in touch with the journal}

1) Table of Contents (TOC) email alert

Receive an email alert containing the TOC when a new complete issue of the journal is made available online. To register for TOC alerts go to www.phcogres.com/signup.asp.

\section{2) RSS feeds}

Really Simple Syndication (RSS) helps you to get alerts on new publication right on your desktop without going to the journal's website. You need a software (e.g. RSSReader, Feed Demon, FeedReader, My Yahoo!, NewsGator and NewzCrawler) to get advantage of this tool. RSS feeds can also be read through FireFox or Microsoft Outlook 2007. Once any of these small (and mostly free) software is installed, add www.phcogres.com/rssfeed.asp as one of the feeds. 